\title{
VOLUMETRIC COLOR APPROACH AS APPLICATION OF VISUAL COLOR IN SPACE ZONING CONCEPT
}

\author{
Qobus Tsaqif 1, Dr. Ully Irma Maulina Hanafiah, M.T. ${ }^{2}$ \\ 12 Interior Design Study Program, Industry Creative Faculty, Telkom University \\ 1'qobusqt@gmail.com, ${ }^{2}$ ullyrmaulinafia@ telkomuniversity.ac.id
}

\begin{abstract}
In the development of interior design, many are applied to create an atmosphere that can create aesthetics and convenience for users. A design can develop through interior elements, especially through color and shape. In a space design with various functions it creates its own zoning at various activities. The emphasis on zoning can be developed through an interior design with the concept of distinct space, by applying various elements that can distinguish space, such as color elements. Volumetric Color approach which uses colors to create a volume of space in an area by using the same color in all interior elements. The difference in color and shape of space creates zoning and function in space to be more specific. In addition to zoning, the use of different and striking colors can provide vocal points and aesthetics in space. The purpose of this descriptive-analysis research is to make a systematic, factual and accurate description, picture, or painting of a case study producing a space with attractive volumetric colors, and as an identity in space. The results of this study can play a role in interior design in the use of color not only as aesthetics of the space, also can provide convenience for users to recognize areas that exist with different functions. In addition, the use of colors in accordance with the function of the area can also be adjusted to affect the psychological space that can have a positive impact on space.
\end{abstract}

Keywords: Volumetric Color, Zoning of Space, Limitation of Space Functions

\section{INTRODUCTION}

The role of interior design is to create a space that can create aesthetics and convenience for space users. Designers have a way and their respective ideas to produce attractive designs that are balanced with a positive impact on users of space through elements in the interior. The design that is developed also needs to be based on aspects related to the activities of users.

Public space is a space that serves as a place to accommodate community activities, both individually and in groups, where the shape of public space is highly dependent on the pattern and composition of the mass of the building / space (Rustam Hakim, 1987). In a public space, the activities carried out vary so as to create a different area. Each area in a public space is grouped according to functions and activities. Development of design in the space used creates zoning to differentiate areas in a large space to facilitate user understanding identity in space. One element in the interior that can be developed to achieve this is the color element.

Color element is often used to develop a design. According to Albert $\mathrm{H}$. Munsell (2000), color is one of the visual elements that can be directly identified and is an important element within the scope of the fine arts and design disciplines. Within the scope of art and design, color can mean a certain reflection of light that is influenced by the pigment found on the surface of an object. Color play as a design development in public spaces is an important thing to do to increase the more aesthetic space.

The notion of color, whether in the form of a harmonious blend, patterns and their meaning is a very important part of the knowledge of artists, architects and designers 
in their work. Color selection refers to activities in space with the aim of influencing user concentration and maximizing the function of an area in a space.

\section{Color As Divider Of Zoning In The Space}

Basically, color is a result of absorption or reflection of light on an object. The results of reflections produced from all colors produce white, while the absorption results all produce black (Color, Space, and Style; 2007: 137). Each interior design has the use of color as an interior element that is used as a media in the aesthetic achievement that the designer wants to produce. According to Mita Purbasari (2000), color is also an effective communication tool to express messages, ideas or ideas without using writing or language.

Each design arrangement can be realized in three dimensions in different ways, which allows interior designers to explore how materials, shapes and structures can be processed to create volumetric compositions that bring a livelier design diagram (Higgins, 2015: 122). In the processing of spatial design, in addition to line elements, materials, floor levels, columns, ceilings, etc., the use of colors can be used to manipulate and provide visual effects to users to form a zone or a different space.

Zoning comes from the basic word zone which means a group of individuals and individuals who are located at one point in the area and have certain activities and relationships. Zoning has an important role to group and divide the area in space so as to create a spatial structure that can optimize the performance of users. In general, a zone and space can be divided through several things, namely, the division of space using lines, materials, leveling, low partitions, partitions with an opening (entrance), pillars and block walls. (Higgins, 2015: 123).

The use of color as an area divider will be more beneficial in open / large spaces. The use of two different colors can form a clearly defined boundary area. Making it easier for users of space in understanding each area with different functions. In addition, the use of color can be used as an element that is able to change the mood of users to be more efficient at work and of course the selection of the right colors can increase the concentration of space users.

\section{METHOD}

The method used in this research is descriptive and analysis. Descriptive method is done by analyzing the design of public spaces that have a color game to create zones based on functions in the area. Through analysis and observation is expected to provide a general description, the results of testing hypotheses, predictions and solutions to a problem. The purpose of this descriptive-analysis research is to make a systematic, factual and accurate description, description, or painting of the facts, properties and relationships between the phenomena investigated. Case studies in this study are Combiwerk, Delft, Playster, and the Elastic office. The three offices apply color to produce attractive visuals, and as identity in space. All three case studies will be analyzed using the volumetric color approach, which not only results in the aesthetics of space, but can also increase the concentration of space users in recognizing and giving perception to the design of the space. 


\section{RESULT AND DISCUSSION}

The use of color in space have been widely used in a design to achieve certain goals. The use of certain colors and application of designs that have good concepts can cause a visual and aesthetic effect on the interior. This application can be found in Combiwerk, Delft. Combiwerk Delft is a Social Workplace (SW) company and offers special work to people who have physical, psychological or mental limitations, and cannot find permanent employment. Even with limited workforce resources and a high desire to work, we need a quality interior design that supports.
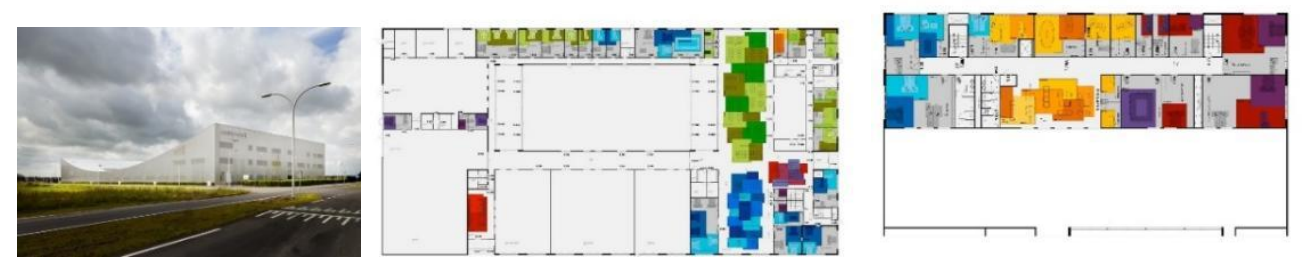

Figure 1 Layout \& Combiwerk Delft Building

The Delft Combiwerk building (figure 1) was designed by VMX Architects in a form completely enclosed by gray monolithic. Not only the color of the building outside, the use of color in the interior in the background with gray covering the floor, walls and ceiling. When entering the building on a gray background interspersed with tertiary gradations that spread (figure 2) and form a zoning.

The use of contrasting colors in the space has a positive psychological impact on the user. The application of shades of red, blue, orange, and green triggers more concentration than the use of shades of gray or white. Kwallek et al. (1996) state that research that has been done on office users shows that office colors do not affect performance, but the rate of workmanship that can be higher in white office space compared with solid colors. The results of the study are in line with the solid colors applied to the Delft Combiwerk.

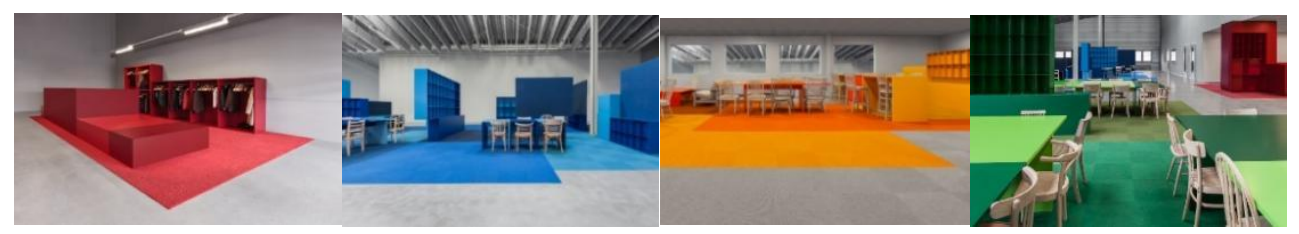

Figure 2 Combiwerk Delft Office Space

The use of color in space can also be found at the Playster office located in Montreal, Canada. Playster is a subscription-based entertainment service company. This office is designed by ACDF Architecture and has an open plan office concept without partitions on different space functions. The background color in the Playster office interior is dominated by the use of white color. Furthermore, the use of solid colors can be found with the aim of defining and differentiating various areas in the office. Without partitions, zoning can be seen in the application of contrasting solid colors applied to these spatial elements, thus creating a different visual impact for the space user.

The choice of tertiary colors applied to the interior are the colors taken from the color of the Playster logo (picture 3), namely yellow, pink, blue and green. The basic color 
of the logo is developed again by using harmonious colors, giving rise to mixed colors, namely: red, orange, green, blue, and purple. The logo shape consisting of a rectangular arrangement influences the application of the color of the floor plan (figure 4) which is applied to the static zoning form and is the order of the rectangular shape.

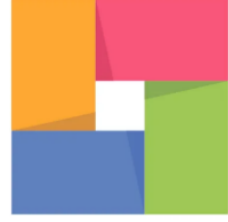

Playster

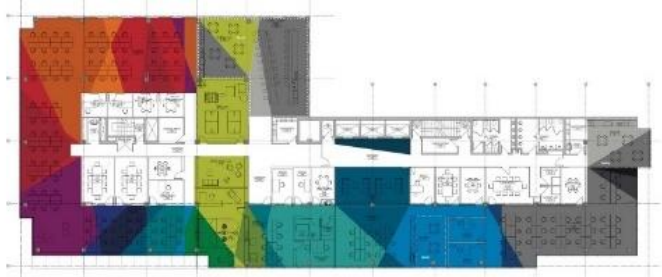

Figure 4 Playster Layout

Figure 3 Playster Logo

The tertiary color consists of 6 colors which are the development of the colors in the office logo. The tertiary color differences used in each area are distinguished and chosen to indicate different divisions in the office. The addition of white in the corridor is functioned to give workers a difference and refreshment from the solid color patterns in the workspace. Visually the impact resulting from the application of contrasting and solid colors forms a barrier and the sustainability of the color patterns in space, as well as the identity of the space which functions to distinguish zoning in space within an open concept. (picture 5).
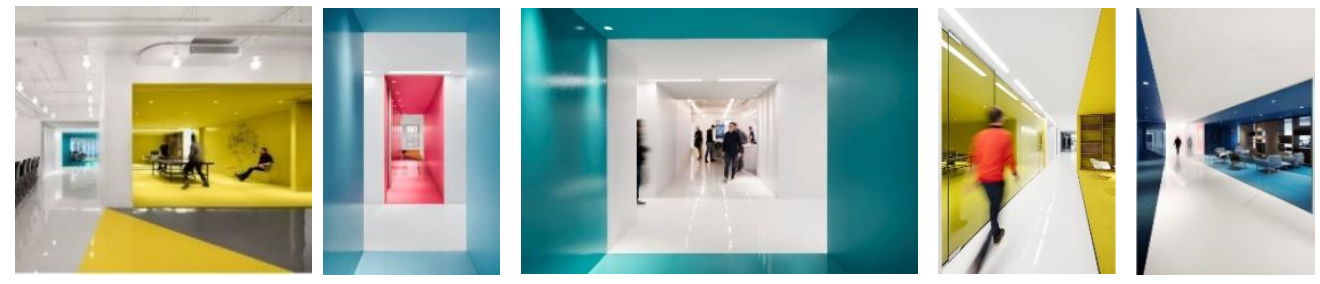

Figure 5 Playster Office Space

The use of color that is applied to the Playster's office is emphasized for the zoning of the work area, besides that the color that refers to the office's identity has a positive impact on increasing the concentration of space users. The results of the application and color produce visual color that add to the aesthetics of space.

The application of colors in similar spatial designs can also be found at the Elastic office in California, United States. Elastic is a company engaged in the field of websites and research. The Elastic office interior design was designed by an architect named Garcia Tamjidi. The concept of open space is found in several areas without the use of partitions or walls. The division of the area is the same as the concept applied to the interior of the Combiwerk and Playster offices which uses tertiary and solid colors. The application of colors to the interior is also a development of the colors in the logo (picture 6) of the Elastic brand. 


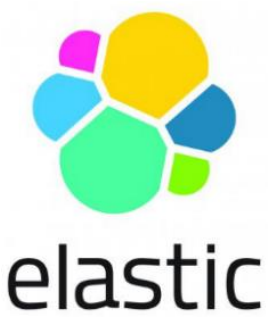

Figure 6 Elastic Logo

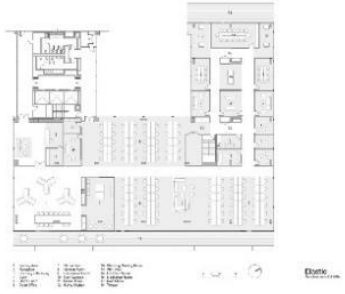

Figure 7 Elastic Layout

A fully open work environment that focuses on presentation and discussion activities. Even with the open plan concept, some rooms with functions with presentation activities still use acoustic materials as wall finishing to reduce the reflection of the sound produced during the presentation. Zoning is created through interior elements that have contrasting color differences. The use of different flooring materials is also applied as zoning of space.
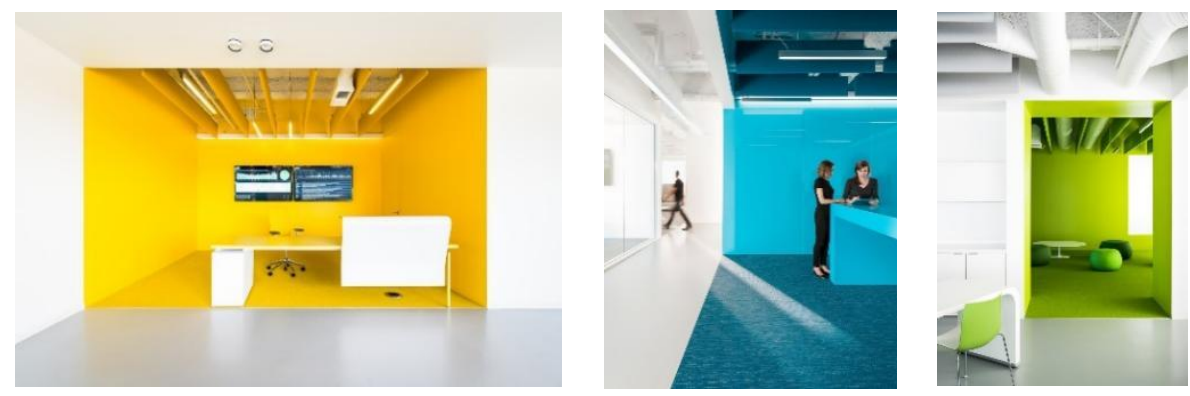

Figure 8. Elastic Office Space

Based on the analysis of precedent studies that have been carried out on three (3) different case studies, the application of color in each spatial design uses a different method. The colors used in the Combiwerk office use Substractive RYB color mixing. Subtractive RYB is a theory of colors that results from mixing three primary primary colors with the aim of avoiding the application of bright colors so that the results of the mixing produce a darker color. (Color, Space, and Style; 2007: 137). Gradation of colors that overlap in some areas having a certain base color applying the RYB Subtractive system which creates a darker color.

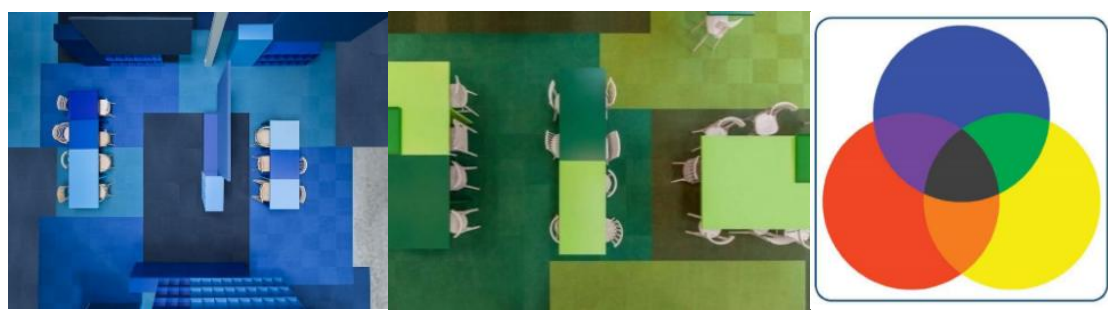

Figure 9. The Use of Colors in Combiwerk Office

The application of these colors in the Combiwerk space is grouped based on their basic colors and gives the distance from the color zoning to the other colors. Based on the contrast color theory expressed by Itten, the color that blankets the entire interior element in space uses gray which is classified as the type of Contrast of Saturation. 


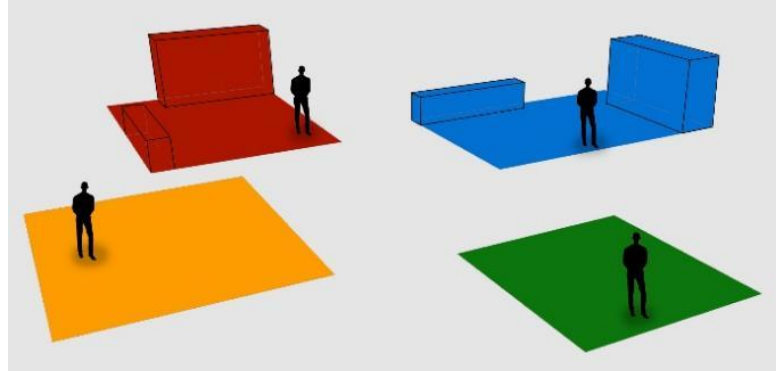

Figure 10. The Use of Colors in Combiwerk Office (3D)

Contrast of Saturation is a gray color enhancer to reduce color intensity and tends to neutralize and the addition of gray can produce effects on colors that are mixed with a certain intensity. (Color, Space, and Style; 2007: 147). How to use contrasting colors helps to provide a nuance that stays in tune despite using contrasting colors, which results in aesthetics of the Combiwerk Deflt space.

In contrast to the way the mixture of colors used by Combiwerk, the Office of Playster and Elastic uses the theory of Additive Color mixing. Additive Color is a combination of primary colors between red, green and blue combined to reach the brightest color point to create three new colors that are recombined to create white. Therefore the color that dominates and is made fromthe base color of the two offices is white.
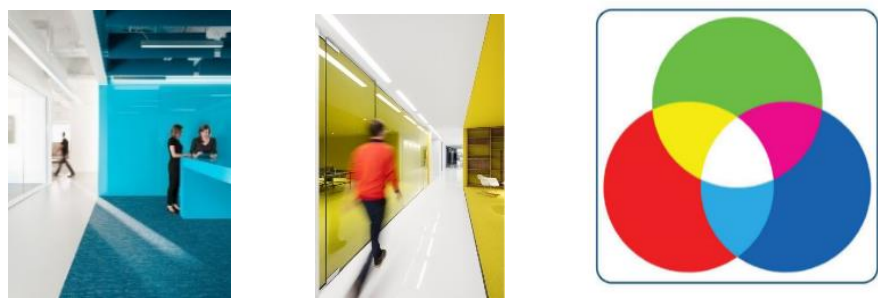

Figure 11. The Use of Colors in Playster dan Elastic Office

The application of colors used in the Playster and Elastic offices is more visible in interior elements, walls and ceilings. The use of colors used can be more felt by the user because the volume of colors produced is more. This creates a stronger visual effect in giving users instructions on the use of colors with different zoning.
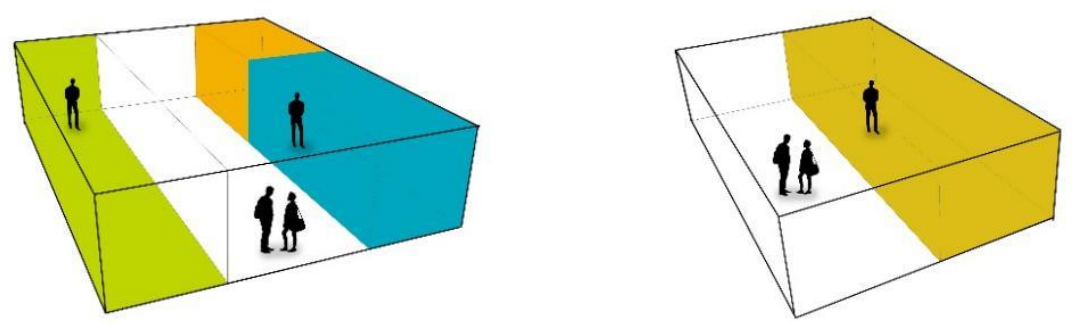

Figure 12. The Use of Colors in Playster dan Elastic Office (3D 
Color schemes are the result of combined color changes and the development of basic colors that are classified according to the color scheme wheel. (Color, Space, and Style; 2007: 142). Based on the existing color theory, designers can combine the colors that exist in these color scheme groups. The similarity between the three places uses a Triadic color scheme. Triadic color scheme is the use of three priner colors at the same time around the color wheel which results in a contrast color scheme.

Volumetric color approach is one of the approaches used to achieve the use of color to produce a volume in space. Color Volumetric Approach is an approach that uses color to create a volume of space in an area by using the same color in all interior elements. This Volumetric approach can be created through the existence of vertical and horizontal elements which have the same color so as to create visual effects on the users of space. The Combiwerk, Playster and Elastic offices take advantage of this approach to divide areas according to function and to create

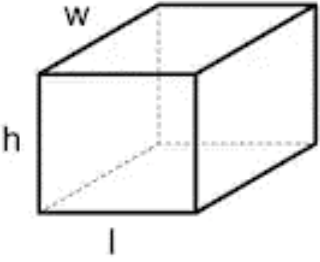

$V=1 \times w \times h$ aesthetics in space by using colors according to their brand. A volume can be produced through a combined vertical or horizontal plane or side. The interior of the volume will not be formed when using different colors, different colors will not provide volumetric visual effects because each side will not look like a plane. The use of the same color will form a field and look as a whole.

Table 1 The use of different colors to produce color volumes in space.

The use of mono color

Table 1 shows the use of different colors will affect the visual effects produced by colors to produce color volumes in space. The volumetric color difference between Combiwerk, Elastic and Polyster is the application of the vertical side. The vertical side which is owned by zoning in space in Combiwerk is the vertical plane produced by the height of the furniture. Whereas the office of the Elastic and Polyster vertical sides are produced by the use of the same color on the walls of the space. The volumetric difference results in an emphasis on the volume of space in the Elastic and Playster offices more felt than with the volume of space in the Combiwerk office. Emphasizing 
the volume of space with the application of color will result in the understanding of space in different zoning will be increasingly clear.

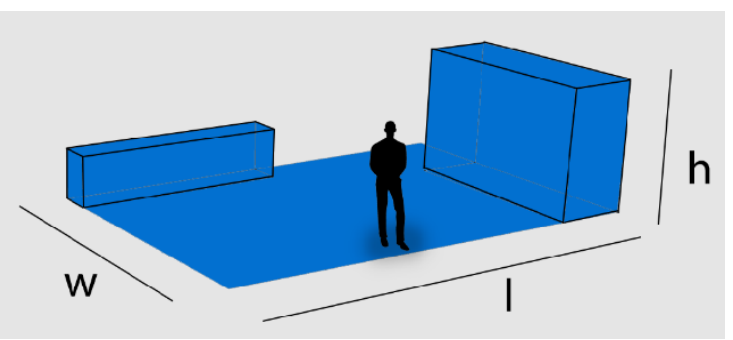

Figure 14. Volumetrik Color in Combiwerk

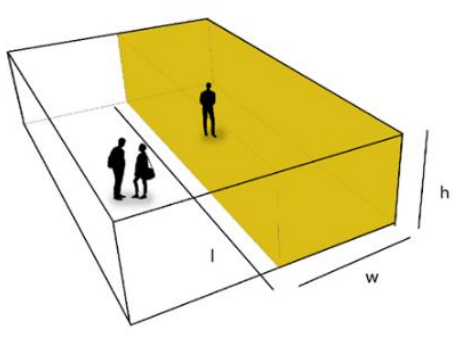

Figure 15. Volumetrik Color in Elastic \& Polyste Office

\section{CONCLUSION}

The design of the interior has various kinds of aspects that can be utilized to maximize the design. Color is one aspect that can be used. Various benefits generated by color in the interior in the form of the application of the analogy to be conveyed to the building owner, have a psychological impact on users of space and aesthetics.

The use of color can also be used as a guide in the division of areas and zoning in space, without the need to use partitions or walls as a barrier. The division can be applied by using contrasting colors that can form a separate zoning. To maintain the aesthetics of the space in the choice of contrasting colors also need to be based on the color theory expressed by Itten. The achievement of a visual effect for dividing zoning in space is also strengthened by the existence of a volumetric color approach. Volumetric colors are formed through the similarity of colors in the surrounding interior elements from both the vertical and horizontal sides of the area so as to provide clarity of the area and function of the space.

\section{REFERENCES}

[1] Ian Higins. 2015. Spatial Strategies For Interior Design.

[2] Mimi Love, Chris Grimley. 2007. Color, Space and Style.

[3] Budi Setiawan, Ulli Aulia Ruki. 2014. Penerapan Psikologi Desain Pada Elemen Desain Interior

[4] Rieka Angkouw, Herry Kapugu. 2012. Ruang Dalam Arsitektur Berwawasan Perilaku

[5] Lawson, Fred, 1976. Hotel Motels and Condominiums (Design Planning and Maintenance), First Publish Great Britain by The Architectural Press LTD, London.

[6] Tiarma Isi Naibaho dan Ully Irma Maulina Hanafia, Analisa Sirkulasi Ruang Gerak Pengguna Pada Area Baca di Perpustakaan Universitas Swasta, Vol. 3, No. 3 , (2016) 2477-0566 
[7] Ananda Trisiana, Ully Irma Hanafiah, dan Titihan Sarihati, Pemanfaatan Konsep Space Within A Space Dalam Pengolahan Layout Pada Interior, Vol. 3, No.1, (2018) 2477-0566

[8] Social 01 / i29 1 interior architects + VMX Architects. 17 Oct 2012. ArchDaily. Accessed 27 Sep 2019. <https://www.archdaily.com/281988/social-01-vmxarchitects-i29-1-interior-architects/> ISSN 0719-888

[9] Elastic / Garcia Tamjidi Architecture Design. 23 May 2015. ArchDaily. Accessed 27 Sep 2019. <https://www.archdaily.com/632016/elastic-garcia-tamjidiarchitecture-design/> ISSN 0719-8884

[10] Mark McMenamin. 2018. Playster by ACDF Architecture: 2017 Best of Year Winner for Midsize Tech Office.

[11] Shruti Hermani, Ravi Mokashi Punekar DoD, IIT Guwahat. Visual Design Colour Theory. http://www.dsource.in/course/visual-design-colour-theory/usecolours-interior-design

[12] Oberfeld D., Hecht H., Gamer M. (2010). Surface lightness influences perceived room height. Q. J. Exp. Psychol. 63 1999-2011. 10.1080/17470211003646161

[13] Marco Costa, Sergio Frumento, Mattia Nese, Lacopo Predieri. 2018. Interior Color and Psychological Functioning in a University. 